\title{
IDŐJÁRÁS
}

Quarterly Journal of the Hungarian Meteorological Service

Vol. 125, No. 4, October-December, 2021, pp. 555-570

\section{Historical observation impact assessments for EUMETNET using the ALADIN/HU limited area model}

\author{
Roger Randriamampianina ${ }^{1, *}$, András Horányi ${ }^{2}$, Gergely Bölöni ${ }^{3}$, \\ and Gabriella Szépszó ${ }^{4}$
}

\author{
${ }^{1}$ Norwegian Meteorological Institute \\ Henrik Mohns Plass 1, Oslo 0371, Norway \\ ${ }^{2}$ European Centre for Medium-Range Weather Forecasts \\ Shinfield Park, RG2 9AX, Reading, UK \\ ${ }^{3}$ Deutscher Wetterdienst \\ Frankfurter Str. 135, Offenbach, 63067, Germany \\ ${ }^{4}$ Hungarian Meteorological Service \\ Kitaibel Pál u. 1., Budapest 1024, Hungary \\ *Corresponding author's E-mail: rogerr@met.no \\ (Manuscript received in final form August 30, 2021)
}

\begin{abstract}
Two historical Observing System Experiment (OSE) studies using the ALADIN limited area model and its assimilation system are described. The first study, using an OSE scenario that minimizes the impacts of observations through the lateral boundary conditions, demonstrated the importance of each assimilated terrestrial (radiosonde, aircraft, and wind profiler) observations on the analyses and short-range forecasts of the ALADIN/HU model and proved evidence, that the role of conventional observations cannot be even partly taken over by satellite measurements without degradation of the forecast quality. The second study demonstrated that the assimilation of radiosonde observations remains indispensable even with a progressively increasing amount of aircraft measurements.
\end{abstract}

Key-words: ALADIN, data assimilation, OSE, observations, limited area model, EUCOS 


\section{Introduction}

Numerical weather prediction (NWP) models have developed enormously during the last three decades (Bauer et al., 2015). Initialization of these models requires a lot of observations in time and (three dimensional) space. To be efficient, most of the observations are synchronized in time and shared between the NWP centers around the world through the Global Telecommunication System (GTS). The World Meteorological Organisation (WMO) is coordinating the management of the observation network on a global scale, while at European scale, EUMETNET provides recommendations and support for the development and maintenance of the terrestrial observing system.

NWP models require regular initialization of their initial condition taking into account all available observations through the data assimilation (DA) process (Daley, 1991; Kalnay, 2002). Therefore, well designed (spatially and temporally) observations are very important for an accurate NWP. For this reason, EUMETNET regularly initiates design studies that aim at evaluating the performance of the existing observation networks and their possible evolution. The Hungarian Meteorological Service (OMSZ) participated in some of these studies in 2006 (first study: EUCOS ${ }^{1}$ Space/Terrestrial Link Study) and 2009 (second study: Upper Air Network Redesign Study), which involved also NWP centers in Europe such as the European Centre for Medium-range Weather Forecasts (ECMWF), Deutscher Wetterdienst (DWD), Met Office, Danish Meteorological Institute (DMI), and Norwegian Meteorological Institute (MET Norway). The evaluation of the "usefulness" of different observation networks is usually done through the examination of the relative impact of these networks on NWP analyses and forecasts. Usually, the following approaches are used for such an evaluation: forecast sensitivity to observation impact (FSOI: e.g., Baker and Daley, 2000; Gelaro et al., 2007; Cardinali, 2009; Soldatenko et al., 2018) and Observing System Experiments (OSEs: e.g., Bouttier and Kelly, 2001; Amstrup, 2008; Benjamin et al., 2009; Radnoti et al., 2012; Bormann et al., 2019). In practice, in OSE the studied observations are either progressively added (e.g., Randriamampianina et al., 2019) or taken out (data denial) (e.g., Lawrence et al., 2019; Randriamampianina et al., 2021) from the DA system, and the impact of such change is investigated.

This paper describes two OSEs initiated by the EUMETNET and realized at OMSZ using the ALADIN² model (Bubnová et al., 1995; Horányi et al., 1996; Termonia et al., 2018) and its assimilation system (Fischer et al., 2005; Bölöni, 2006; Randriamampianina, 2006b; Mile et al., 2015). While the first study aimed at studying the benefits of terrestrial observing systems on top of the available satellite observations, the second study investigated the relative impact of different timely and spatially designed aircraft and radiosonde measurements.

EUMETNET Composite Observing System

Aire Limitée Adaptation dynamique Développement InterNational 
A limited area model (LAM) requires lateral boundary conditions (LBC) to compute the forecasts for the region of interest, which are usually provided by a global model, also called the driving model. With respect to LAM data assimilation and OSEs, it is of particular importance what kind of observations are assimilated in the driving model. Practically, there are few possible options: 1) more observation types are used in the driving model compared to those used in LAM; 2) less observation types are used in the driving model compared to those used in LAM; 3) similar observation types are used in both driving model and LAM. Option 1) is valid for most of the operational LAMs in Europe. In the first study, 2) was used to minimize the impact of the observations assimilated in the driving model in LAM, while 3) was used in the second study to get full impact of the observations also through the LBCs in LAM. Although the relative impact of observations through LBCs were well considered in the presented two studies in this paper, their contribution in LAM was only evaluated in detail in recent studies (Randriamampianina et al., 2021).

Section 2 describes the applied ALADIN/HU assimilation and forecast systems, the experimental designs, and the adopted verification approach. Section 3 presents the obtained results, while conclusions and some discussion are included in Section 4.

\section{Data and methods}

\subsection{ALADIN/HU assimilation and forecast systems}

In this study the hydrostatic ALADIN model was used for Hungary (ALADIN/HU; see Fig. 1 for the model domain) (code version CY28T3 for the first and CY30 for the second study which were the operational model versions in 2006 and 2009, respectively) with slightly different configurations in the two OSEs (Table 1). Three-dimensional variational data assimilation (3D-Var Fischer et al., 2005) was applied to provide the atmospheric analysis using conventional (surface, radiosonde, aircraft, wind profiler) wind retrievals (atmospheric motion vectors: AMV) (Randriamampianina, 2006a) and satellite radiances (ATOVS: AMSU-A and AMSU-B) (Randriamampianina, 2005, 2006b) observations. 


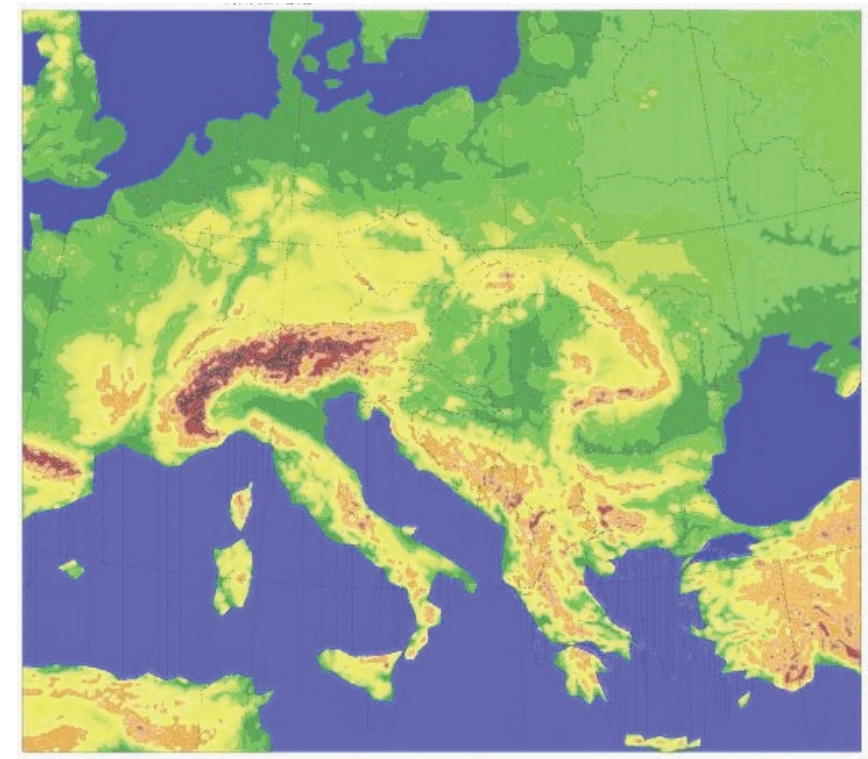

Fig. 1. The domain of the ALADIN/HU model

Table 1. The applied model setups in both studies

\begin{tabular}{lcc}
\hline \hline & First study & Second study \\
\hline \hline Horizontal resolution & $12 \mathrm{~km}$ & $8 \mathrm{~km}$ \\
Vertical resolution & 37 vertical levels from the & 49 vertical levels from the \\
& surface up to $5 \mathrm{hPa}$ & surface up to $5 \mathrm{hPa}$ \\
Code version & CY28T3 & CY30 \\
Initial times and forecasts lengths & 00 UTC (48h) & 00 UTC (54h) \\
& 12 UTC (48h) & 06 UTC (48h) \\
\hline
\end{tabular}

Although the use of observations was mainly determined by the scenarios of the OSE (see the next sections on the design of the experiment), here we describe some details on the use of observations, which might be important when interpreting the obtained results later on. Among the surface (SYNOP) observations, only geopotential data was used. From radiosondes (TEMP), geopotential, temperature, wind, and humidity data were assimilated. The AMDAR (Aircraft Meteorological Data Relay) aircraft data were assimilated with $25 \mathrm{~km}$ horizontal thinning within a $+/-1$ hour observation window. The default thinning procedure of the aircraft data in ALADIN is done separately for each flight, which implies a risk of data being close to each other in space but measured 
at different times. To avoid this problem, an additional filtering procedure was applied prior to aircraft data thinning. Wind profiler observations were used between $700 \mathrm{hPa}$ and $400 \mathrm{hPa}$ from the closest profile to the analysis time. This definitely results in a small amount of data in the experiments. The AMV (GEOWIND) data were used above $350 \mathrm{hPa}$ and below $800 \mathrm{hPa}$ over sea from the closest observation to the analysis time with a $25 \mathrm{~km}$ horizontal thinning (Randriamampianina, 2006a). Full grid ATOVS (AMSU-A and AMSU-B/MHS) data were assimilated within a $+/-3$ hour observation window using $80 \mathrm{~km}$ horizontal thinning. In the experiments AMSU-A data from NOAA-15 and NOAA-16, and AMSU-B data from NOAA-16 and NOAA-17 were used (Randriamampianina, 2005 and 2006b). The data usage in the OSE experiments was carefully assessed through a web-based monitoring system.

For the first study, the surface fields were initialized by an interpolation of the corresponding ECMWF analysis to the ALADIN grid, while for the second study, an optimum interpolation (OI) scheme was used for the initialization of the surface fields. Concerning the assimilation of satellite radiances, the RTTOV-7 radiative transfer code was used to simulate the radiances from the model fields (Saunders et al., 2002). The background error covariance matrix is computed using the NMC method (Parrish and Derber, 1992) in the first study and by the downscaled ensemble method (Berre et al., 2006; Bölöni and Horvath, 2010) in the second study. A digital filter initialization is applied prior to the model integration. A six-hourly assimilation cycle generating analyses at $00,06,12$, and 18 UTC was adopted. Three-hourly lateral boundary coupling was applied using the ECMWF analyses and short-range forecasts depending on the network time. At 00 and 12 UTC, the ECMWF analyses were used as the first boundary file, while at 06 and $18 \mathrm{UTC}$, the short-range forecasts (6-hour forecasts) of the ECMWF were used as the first coupling file. Longer forecasts were performed twice a day (see Table 1).

\subsection{Design of the experiments}

\subsubsection{First study}

The objective of the EUCOS Space/Terrestrial Link Study was to explore the relative benefit of various components of the terrestrial observing system on top of satellite observations. The chosen strategy for the study was to run a series of data denial experiments using different sets of observations within both global and LAM assimilation and forecasting systems. The NWP models taking part in the experiments were the global ECMWF, the global and the LAM version of the Unified Model (UK MetOffice), the Danish (Amstrup, 2008) and the Norwegian (Thyness and Schyberg, 2007) versions of the HIRLAM ${ }^{3}$ model, and the ALADIN/HU model. Due to the different location of the LAM domains, the OSE

HIRLAM: High Resolution Limited Area Model 
scenarios differed slightly between the participants with LAM. For instance, in the Hungarian experiments the E-ASAP (EUMETNET Automated Shipboard Aerological Programme) observations were not used, because these observations cover mainly the northern part of the Atlantic ocean. Lateral boundary conditions for the ALADIN- and HIRLAM-model based experiments were taken from the ECMWF baseline (see below the description of baseline) experiment. The Unified LAM Model was coupled with its global version.

The experiments were conducted for both winter and summer periods. The winter period was from December 4, 2004 till January 20, 2005, while the summer period started on July 15 and lasted until September 5, 2005. The first 10 days of both periods were used for a warm up of the model and were not used for verification. The definitions and acronyms of the ALADIN/HU experiments are as follows:

Winter (EU)/Summer (ES) experiments:

EU01/ES01 - baseline $\left(\mathrm{GSN}^{4}\right.$ surface and GUAN ${ }^{5}$ radiosonde + AMV + ATOVS radiances)

EU02/ES02 - baseline + aircraft,

EU03/ES03 - baseline + radiosonde wind profiles,

EU04/ES04 - baseline + radiosonde wind and temperature profiles,

EU05/ES05 - baseline + wind-profilers,

EU06/ES06 - baseline + radiosonde wind and temperature + aircraft,

EU07/ES07 - baseline + radiosonde wind, temperature and humidity,

EU08/ES08 - full observation (radiosonde + wind-profiler + aircraft).

\subsubsection{Second study}

The main objective of the Upper Air Network Redesign Study was to provide input for the definition of a European-wide network of ground-based upper-air observing systems with special emphasis on regional modeling. This study concentrated on the possible refinement of the upper-air observing network (radiosonde and aircraft) with respect to their optimal spatial and temporal distribution. For that end, six different observation scenarios were specified starting from the full operational data usage (control scenario) and ending with a baseline scenario, which was characterized by radical decrease of the number of radiosonde and aircraft profiles. The intermediate scenarios were focusing on the different thinning distances for the radiosonde and aircraft data with step-by-step degradation of their amounts. The scenarios were defined as follows:

Sc2 - Control: Full operational observation coverage.

GSN: GCOS (Global Climate Observing System) Surface Network

GUAN: GCOS Upper-Air Network 
Sc3a: The radiosonde network is slightly reduced with a $100 \mathrm{~km}$ thinning distance, all aircraft data and the full remaining part of the observation networks.

Sc3b: Like Sc3a, but no thinning is performed for the $00 \mathrm{UTC}$ radiosonde profiles.

Sc4: Like Sc3a but $250 \mathrm{~km}$ thinning distance for radiosondes and aircraft data.

Sc5: Like Sc4, but $500 \mathrm{~km}$ thinning distance.

Sc1 - Baseline: GUAN radiosonde network, flight level aircraft data, aircraft profiles of less than 3 hourly visited airports and full remaining part of the observation network.

The Observing System Experiments based on the above scenarios were performed by a global NWP center (ECMWF) and some National Meteorological Services (NMS) running LAMs. It was decided that the information on aircraft observations (which were created by a special blacklisting and thinning algorithms and provided by the EUCOS team) for each scenario was provided directly by ECMWF in order to ensure, that the same sets of observations are used in both global and limited area experiments. Concerning the radiosonde data, the same blacklisting decisions were applied at all centers. Other observation types were used as locally applied operationally. The experiments were carried out for a winter period between December 15, 2006 and January 31, 2007 and for a summer period between June 1st and July 15, 2007. The difference between the radiosonde and aircraft observation usage for all scenarios can be seen in Fig. 2, where (for the winter period) the amount of active data is displayed for each scenario. It can be seen that the control scenario is using more than double (rather 2.5) times more amount of radiosonde and roughly double aircraft data with respect to the baseline scenario (these are the two extreme scenarios), and the intermediate scenarios are situated between these two extremes as expected. In terms of aircraft data usage the control ( $\mathrm{Sc} 2), \mathrm{Sc} 3 \mathrm{a}$, and $\mathrm{Sc} 3 \mathrm{~b}$ scenarios are equivalent. Therefore, it is expected that the best forecasting performance is going to be for $\mathrm{Sc} 2$ (control), which is followed by $\mathrm{Sc} 3 \mathrm{~b}, \mathrm{Sc} 3 \mathrm{a}, \mathrm{Sc} 4, \mathrm{Sc} 5$, and $\mathrm{Sc} 1$ (baseline). It is interesting to notice the Christmas and New Year radical decrease in the amount of data especially for the aircraft observations. 

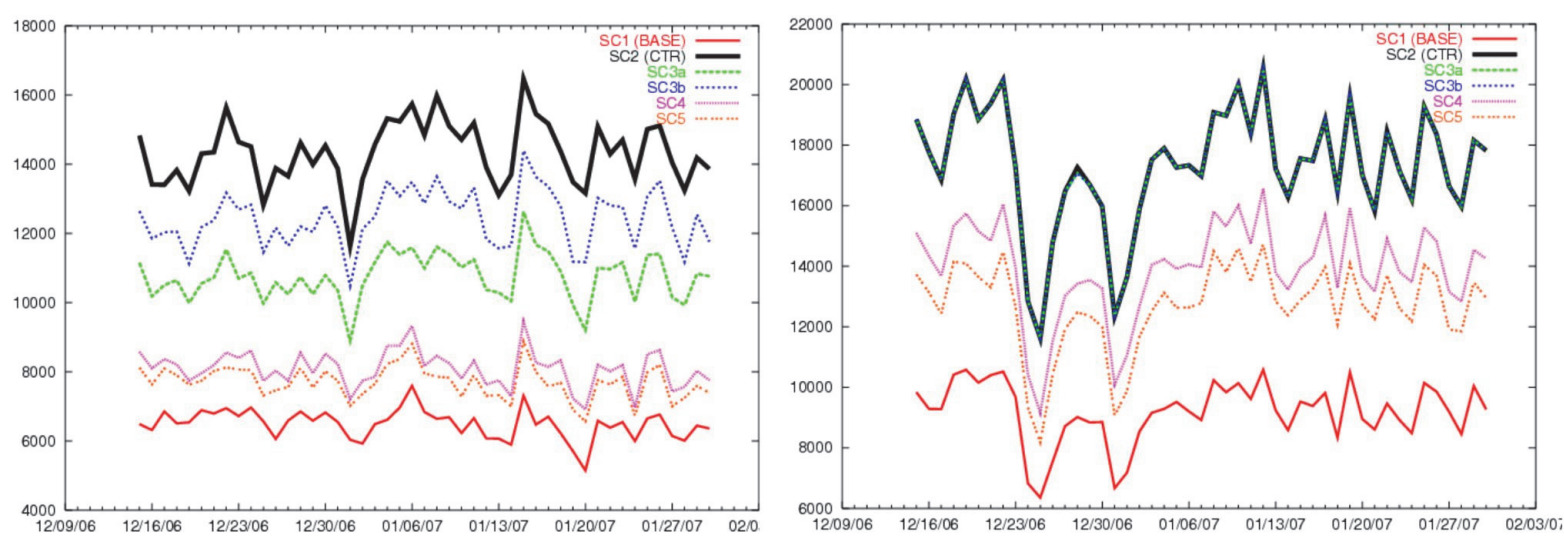

Fig. 2. Number of daily observations (temperature, wind, geopotential, and humidity for radiosondes, and temperature and wind for aircrafts) assimilated into the ALADIN/HU model using the six winter scenarios for radiosondes (left) and for aircraft (right) observations.

In order to be in agreement with the "real-life" situation, the LAM models were coupled with the corresponding global scenario runs (in contrary to the solution proposed for the previous space-terrestrial study - first study -, where the baseline scenario was used for all the runs in order to not mix the impacts of the initial and lateral boundary conditions). The LAM runs were performed by the HIRLAM group and the Hungarian Meteorological Service.

\subsection{The applied verification method}

In order to allow a meaningful comparison of the results from all participants, a common evaluation procedure was agreed, as follows. Computation of objective scores composed by bias and root-mean-square error (RMSE) of the simulated analyses and forecasts against observations (surface and radiosonde observations, using the so-called EWGLAM station list (Hall, 1987)) was mandatory for both studies. For the first study, we also performed a verification against the ECMWF analyses. Geer (2016) underlines the importance of significance of the RMSE differences. Significance tests of the objective verification scores were performed. The significance tests were computed on the normalized (by mean scores) mean difference in analyses and forecasts quality using the Student's t-test. The number of the analyzed and forecast parameters with the associated pressure levels was also agreed in advance. Further, an objective evaluation of two, a summer and a winter, case studies was performed focusing on interesting weather situations. Although, for the sake of the length of this article, the results of these case studies are not discussed. 


\section{Results}

\subsection{First study}

The OSE technique applied in the first study was based on adding the studied observations in DA on top of the baseline system. For example, the impact of the aircraft observations was checked by comparing the verification scores for EU02/ES02 and EU01/ES01. The relative impact of the aircraft temperature and wind data was shown by plotting the verification scores of the above experiments together with the results of the run using the full observation set (EU08/ES08). Similarly, the impact of radiosonde wind data was checked by comparing the verification scores of EU03/ES03 with EU01/ES01, and so on for the impact of the radiosonde temperature, humidity, and the combined impact of radiosonde and aircraft data, as well as for the impact of the wind profilers. As an example, in Fig. 3 we show the impact of the radiosonde temperature on analyses and forecasts of temperature fields.
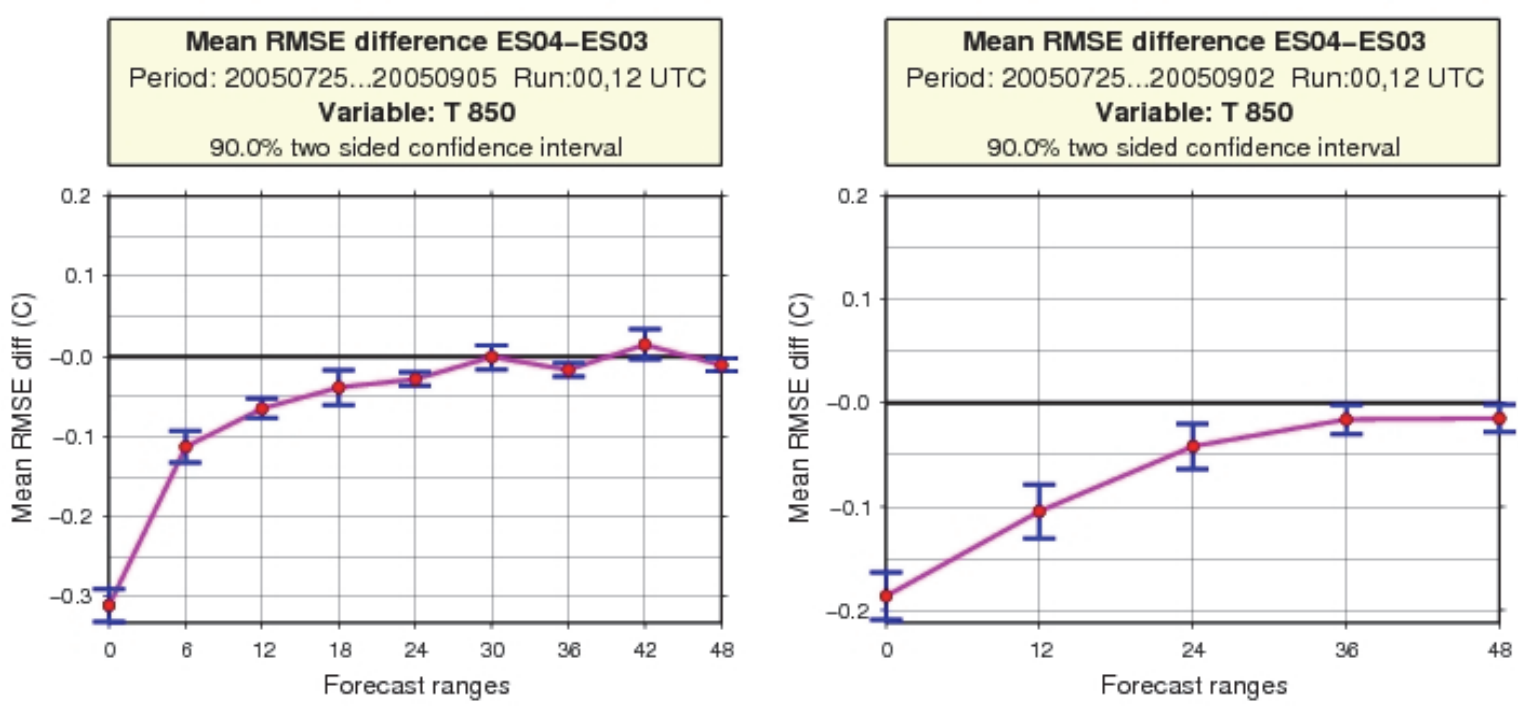

Fig. 3. The RMSE differences of temperature at $850 \mathrm{hPa}$ between the experiment with radiosonde temperature and wind profiles (ES04) and the experiment with radiosonde wind profiles (ES03). The significance test is based on daily scores of temperature fields for both 00 and 12 UTC runs for the summer period July 25-September 2,2005). The graphs show the comparison against observations (left) and against the ECMWF analyses (right). Negative values mean reduction of the model errors when the radiosonde temperature was added in the DA, hence they show positive impact.

Table 2 shows the overall observed (from both against observations and the ECMWF analyses) verification results, which can be summarized as follows. 
Objective verification against ECMWF analyses mostly showed a clear positive impact of the terrestrial observations on the analysis and forecasts of ALADIN/HU up to 2 days. Verification against observations showed that the impact is up to 24 hours. Case studies indicated clear improvement in the forecasts when adding the different components of the terrestrial observations in the assimilation system (not shown).

Table 2. Overall impact of the terrestrial observations during winter (in brackets) and summer (without brackets). + means significant positive impact.

\begin{tabular}{ccccccc}
\hline \hline \multirow{2}{*}{$\begin{array}{c}\text { Observing } \\
\text { system }\end{array}$} & Parameters & \multicolumn{5}{c}{ Forecast ranges with impact } \\
\cline { 2 - 6 } Radiosonde & $\begin{array}{c}\text { Neutral/Fe } \\
\text { w hours }\end{array}$ & $\mathbf{1} / 2$ day & $\mathbf{1}$ day & $\mathbf{1 . 5}$ day & 2 days \\
\cline { 2 - 7 } & Wind & & $(+)$ & & + & + \\
\cline { 2 - 7 } & Temperature & & & $(+)$ & & + \\
\cline { 2 - 7 } Aircraft & $\begin{array}{c}\text { Humidity } \\
\text { temperature }\end{array}$ & $(+)$ & & $(+)$ & & + \\
\hline Wind-profiler & Wind & $(+)$ & + & & \\
\hline
\end{tabular}

A more pronounced and long-lasting positive impact of the aircraft observations was found during summer compared to the winter period. Positive impact of the aircraft data on the forecast of humidity fields was observed during summer, while negative impact was found for the winter period, although it was significant only for a few hours (not shown). Positive impact of the aircraft data on the forecast of precipitation was observed for the summer period, while neutral (from 00 UTC) and negative (from 12 UTC) impacts were found for the winter period (not shown).

A clear positive impact of the radiosonde wind observation on the analysis and short-range forecasts was observed. A positive impact of the radiosonde temperature up to 24 and 48 hours was concluded during the winter and summer periods, respectively. Clear positive impact of the radiosonde temperature forecasts of the mean sea level pressure up to 24 hours was detected for summer, while neutral impact was found during the winter period (not shown). Neutral impact of the radiosonde humidity on the mean sea level pressure was observed during the summer period, while clear positive impact was seen during the winter period. Better impact of the radiosonde temperature on the geopotential was found 
in the summer study. Large positive impact of the radiosonde humidity was observed for all forecast ranges of precipitation (see Fig. 4).

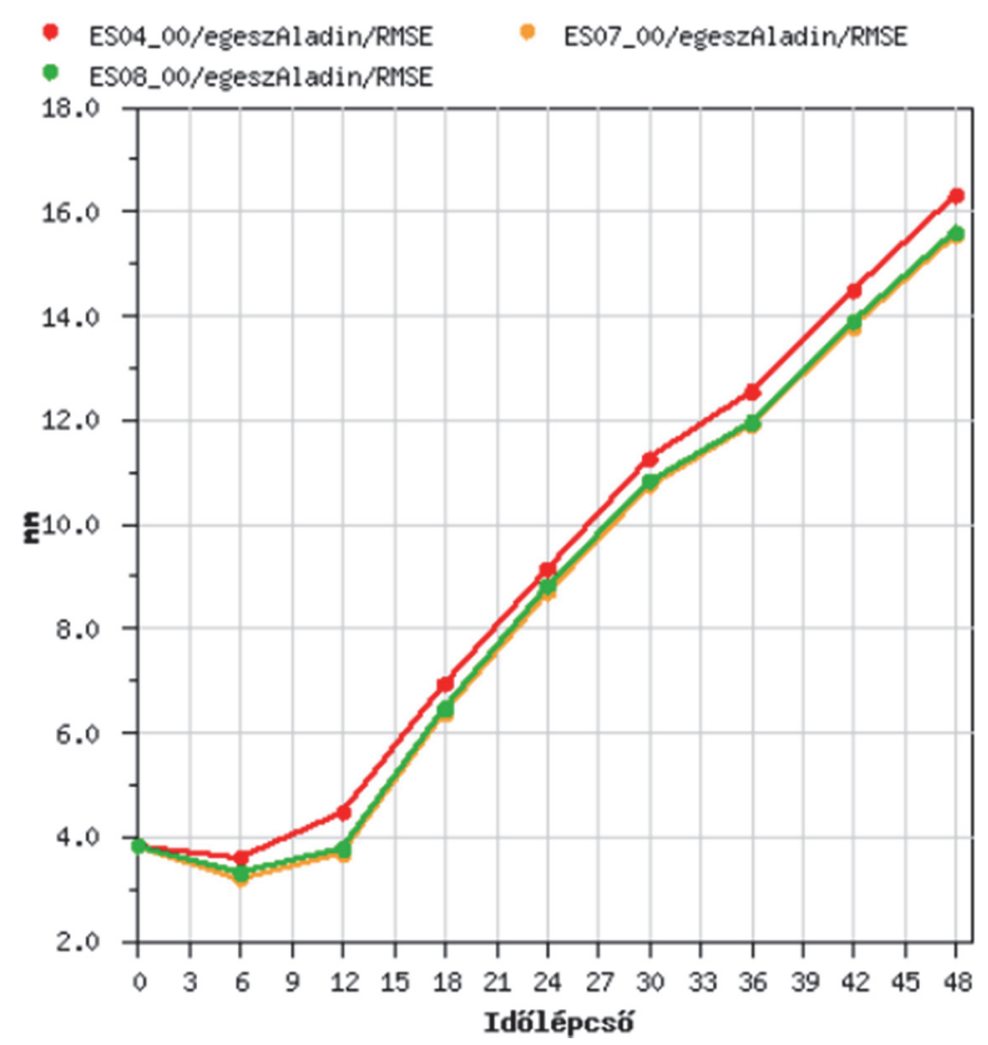

Fig. 4. RMSEs of 6-hourly cumulated precipitation at different forecast ranges (időlépcső - forecast ranges) for 00 UTC runs. Red line: forecasts initialized using radiosonde temperature and wind data (ES04_00), yellow line: forecasts initialized using radiosonde temperature, wind, and humidity data (ES07_00), green line: forecasts initialized with all available data (ES08_00).

The impact of the wind profilers on the analysis and forecasts is neutral for most of the meteorological parameters, but one can find examples with slightly positive impact as well (maximum up to 12 hours).

Our results showed that there is no problem of redundancy when using the aircraft observations on top of the radiosondes. Comparing the baseline (ES01), baseline and aircraft (ES02), and baseline and radiosonde wind and temperature (ES04) (summer study), we found that the impact of the aircraft (wind and temperature) observations was a bit larger than what we found during the winter study (half of the impact of radiosonde wind and temperature data). For the summer period, better scores were observed when comparing the impact of the aircraft data on top of the radiosonde wind and temperature data (ES04 vs ES06), while small deterioration was observed in the winter study. 


\subsection{Second study}

Similarly to the first study, the impact on the ALADIN/HU analysis and forecasts was checked by comparing the verification scores of the different scenarios. Table 3 summarizes the observed verification results focusing on the impact on the analyses and forecasts in the lower troposphere and focusing only on the model run from $00 \mathrm{UTC}$.

The control $(\mathrm{Sc} 2)$ scenario significantly outperforms the baseline $(\mathrm{Sc} 1)$ scenario during the first 24 hours of forecasts with the exception that the impact of temperature lasts up to one and half days in the winter case (Table 3, first comparisons).

Concerning scenarios 3 ( $3 a$ and $3 b$ ), comparing the verification scores of the control with that of $\mathrm{Sc} 3 \mathrm{a}$ showed clear importance of high resolution radiosonde network in LAM. Comparing the verification scores of Sc3a and Sc3b showed the importance of having a full network of radiosonde observations at 00 UTC. The obtained results showed also that $\mathrm{Sc} 3 \mathrm{~b}$ is better than the control (not shown in Table 3).

Table 3. Overall impact of observations with the different scenarios during winter (in brackets) and summer (without brackets). - means significant degradation and positive impact.

\begin{tabular}{|c|c|c|c|c|c|c|}
\hline \multirow[t]{2}{*}{ Observing system } & \multirow[t]{2}{*}{ Parameter } & \multicolumn{5}{|c|}{ Forecast range with impact } \\
\hline & & $\begin{array}{c}\text { Neutral/few } \\
\text { hours }\end{array}$ & $1 / 2$ day & 1 day & 1.5 day & 2 days \\
\hline \multirow{3}{*}{$\begin{array}{c}\text { Control } \\
\text { (Sc2-Sc1) }\end{array}$} & Wind & & & $(-)-$ & & \\
\hline & Temperature & & & - & $(-)$ & \\
\hline & Humidity & & & $(-)-$ & & \\
\hline \multirow{3}{*}{$\begin{array}{c}\text { Radiosonde } 100 \mathrm{~km} \\
\text { thinning } \\
(\mathrm{Sc} 2-\mathrm{Sc} 3 \mathrm{a})\end{array}$} & Wind & $(-)-$ & & & & \\
\hline & Temperature & - & $(-)$ & & & \\
\hline & Humidity & $(-)$ & - & & & \\
\hline \multirow{3}{*}{$\begin{array}{l}\text { Full radiosonde } \\
\text { resolution at } 00 \mathrm{UTC} \\
(\mathrm{Sc} 3 \mathrm{~b}-\mathrm{Sc} 3 \mathrm{a})\end{array}$} & Wind & $(-)-$ & & & & \\
\hline & Temperature & $(-)$ & & - & & \\
\hline & Humidity & & $(-)-$ & & & \\
\hline \multirow{3}{*}{$\begin{array}{l}\text { Radiosonde and } \\
\text { aircraft at } 250 \mathrm{~km} \\
\text { resolution } \\
(\mathrm{Sc} 2-\mathrm{Sc} 4)\end{array}$} & Wind & $(-)-$ & & & & \\
\hline & Temperature & - & $(-)$ & & & \\
\hline & Humidity & & $(-)$ & & - & \\
\hline \multirow{3}{*}{$\begin{array}{l}\text { Radiosonde and } \\
\text { aircraft at } 500 \mathrm{~km} \\
\text { resolution } \\
(\mathrm{Sc} 2-\mathrm{Sc} 5)\end{array}$} & Wind & - & $(-)$ & & & \\
\hline & Temperature & & & & $(-)-$ & \\
\hline & Humidity & & & $(-)$ & - & \\
\hline
\end{tabular}


Further reducing the resolution of both radiosonde and aircraft networks ( $\mathrm{Sc} 4$ and Sc5) showed clear degradation of the accuracy of analyses and forecasts of the ALADIN/HU model. While for the case of Sc4 (both radiosonde and aircraft networks at $250 \mathrm{~km}$ resolution), the degradation in wind and temperature forecast quality lasted up to 12 hours, for Sc5 (both radiosonde and aircraft network at 500 $\mathrm{km}$ resolution), the degradation lasted up one and half day for both temperature and humidity (see Fig. 5). Further, it was clearly shown that degradation of these observing networks significantly impacts the quality of the humidity forecasts of the ALADIN/HU model.
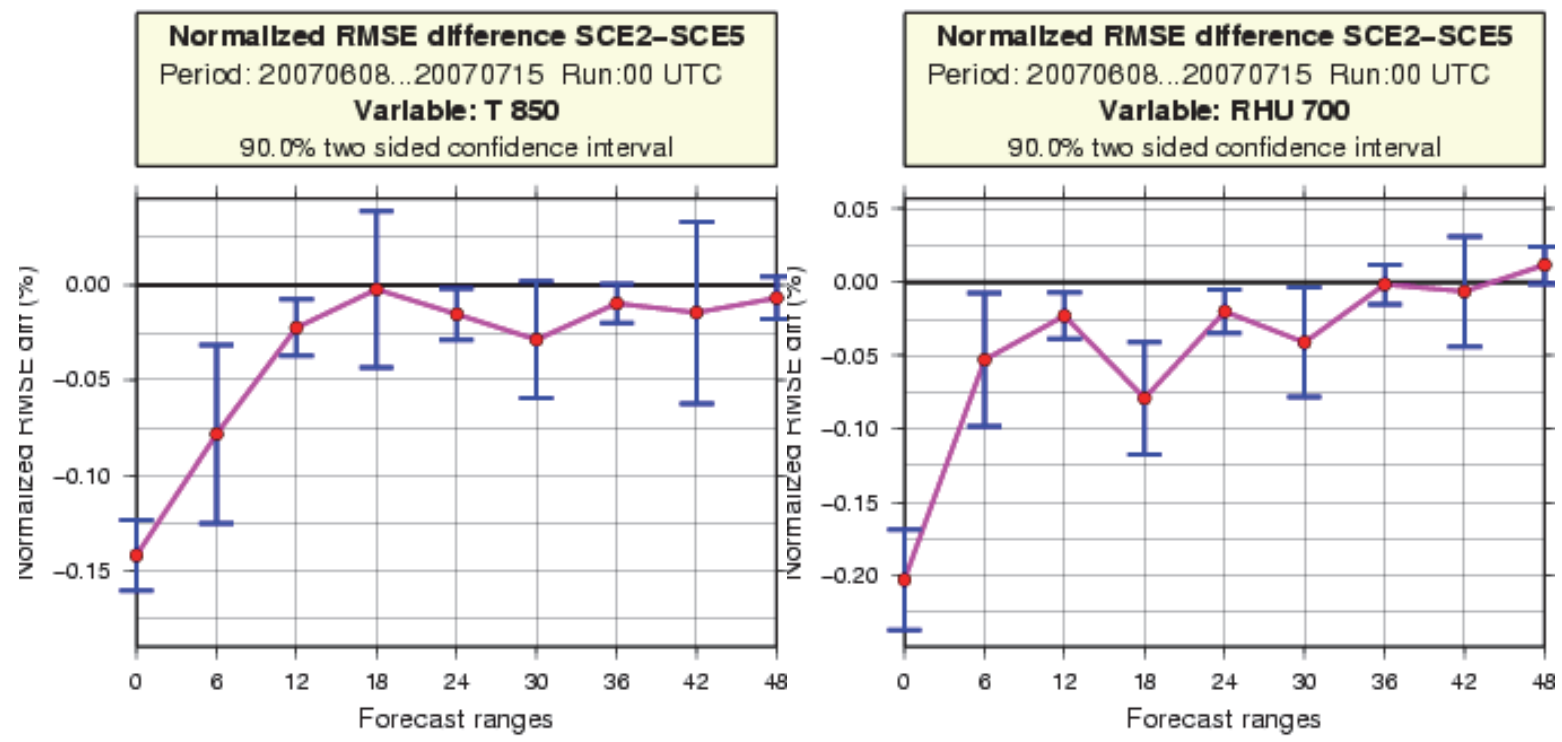

Fig. 5. The RMSE differences of temperature at $850 \mathrm{hPa}$ (left) and relative humidity (right) between the control experiment $(\mathrm{Sc} 2)$ and the one where radiosonde and aircraft data have been reduced with a $500 \mathrm{~km}$ thinning distance $(\mathrm{Sc} 5)$. The graphs show the comparison against observations for the summer period of June 8 - July 15, 2007. Note that the full radiosonde network is mainly available at 00 and 12 UTC, and we have relatively less observations at 06 and 18 UTC. So, the relatively large error bars at 06, 18, 30, and 42 hour forecast ranges are due to use of less verifying observations and not due to the observation impact. Negative values mean reduction of the forecast errors due to the usage of radiosondes and aircraft data with a higher spatial density.

\section{Summary and discussions}

We presented two OSE studies performed several years ago in this paper. While the first one investigated the importance of the full terrestrial (radiosonde, aircraft and wind profiler) European networks, the second study evaluated the efficiency of the radiosonde and aircraft networks. 
In the first study, the impact of the studied observations lasted longer during summer than during winter. All tested observations have clear positive impact on the ALADIN/HU analyses and forecasts. This study showed for the first time that the implemented data assimilation system is working properly, which means that, with the adopted experiment design - minimizing the impact coming through the lateral boundary conditions by using the baseline experiment from the coupling global model -, all the implemented observations showed clear positive impacts on the LAM model.

The second study showed that high resolution observing networks (both radiosonde and aircraft) are important for improving the LAM analyses and forecasts. The positive impacts of the studied observations were clearly shown thanks to the design of the experiments. In the second study, in each experiment the LAM was coupled with its global counterpart. Compared to the impact found in the first study, which was somehow maximized, we got the exact relative impacts of the studied observations through LAM DA. Randriamampianina et al. (2021) used the similar experiment design, and further computed as well the impacts of different observing networks through the LBCs on the LAM analyses and forecasts. They found that the total impacts of observations on LAM upperair forecasts is dominated by the impacts through LBCs. This explains the "relatively weakened" (e.g., shorter lasting) impact shown in the second study compared to what is shown in the first one.

These studies demonstrated that the conventional (terrestrial) observations are still a very important component of the observing network. Despite the large amount of data from new observation techniques (especially satellites), the terrestrial network is indispensable for maintaining forecast quality even on a regional scale, and its redundancy is out of question. Additionally, the increasing number of aircraft data available does not mean that the radiosonde information would become redundant, and therefore, it is critical to keep (or even enhance) the present network of radiosondes.

This paper describes results of studies that were done 10-15 years ago accounting older model versions and relatively poorer observing networks. This is true for the aircraft observations where now we have on top of the AMDAR (Aircraft Meteorological Data Relay) network, the Mode-Selective (Mode-S) Enhanced Surveillance (EHS) and Meteorological Routine Air Report (MRAR) observations. Further, although with very limited numbers, over the Hungarian modeling area of interest, some aircrafts are equipped with humidity sensors. When available, the AMDAR humidity observations are assimilated in the operational convection-permitting AROME (Application of Research to Operations at Mesoscale) model at OMSZ (Tóth et al., 2021). The implementation of the Mode-S (both EHS and MRAR) data is ongoing in AROME/HU (Fischer et al., 2017). We expect different impacts of the individual and combined terrestrial observing networks in the current AROME operational model. 
Acknowledgements: The authors would like to thank Sándor Kertész, Andrea Lörincz and Edit Adamcsek for their contributions to the accomplishment of the two presented studies. We are grateful to ECMWF and EUMETNET, respectively, for providing the lateral boundary condition files, blacklist information, and the verification package, and for the financial support of the studies.

\section{References}

Amstrup, B., 2008: Assessment of the impact of key terrestrial observing systems using DMI-HIRLAM. Quart. J. Roy. Meteor. Soc. 134, 985-1001. https://doi.org/10.1002/qj.249

Baker, N. and Daley, R., 2000: Observation and background adjoint sensitivity in the adaptive observation-targeting problem. Quart. J. Roy. Meteor. Soc. 126, 1431-1454. https://doi.org/10.1002/qj.49712656511

Bauer, P., Thorpe, A., and Brunet, G., 2015: The quiet revolution of numerical weather prediction. Nature 525, 47-55. https://doi.org/10.1038/nature14956

Benjamin, S.G., Jamison, B.D., Moninger, W.R., Sahm, S.R., Schwartz, B.E., and Schlatter, T.W., 2009: Relative short-range forecast impact from aircraft, profiler, radiosonde, VAD, GPS-PW, Metar, and Mesonet observations via the RUC hourly assimilation cycle. Mon. Weather Rev. 138, 1319-1343. https://doi.org/10.1175/2009MWR3097.1

Berre, L., Stefanescu, E.S., and Belo Pereira, M., 2006: The representation of the analysis effect in three error simulation techniques. Tellus 58, 196-209. https://doi.org/10.1111/j.1600-0870.2006.00165.x

Bormann, N., Lawrence, H., and Farnan, J., 2019: Global observing-system experiments in the ECMWF assimilation system. ECMWF Tech. Memo. 839.

Bouttier, F. and Kelly, G.A., 2001: Observing-system experiments in the ECMWF 4D-Var assimilation system. Quart. J. Roy. Meteor. Soc. 127, 1469-1488. https://doi.org/10.1002/qj.49712757419

Bölöni, G., 2006: Development of a variational data assimilation system for a limited-area model at the Hungarian Meteorological Service, Idöjárás 110, 309-329.

Bölöni, G. and K. Horvath, 2010: Diagnosis and tuning of background error statistics in a variational assimilation system. Idöjárás 114, 1-21.

Bubnová, R., Hello, G., Bénard, P. and Geleyn, J.-F., 1995: Integration of fully-elastic equations cast in the hydrostatic pressure terrain-following coordinate in the framework of the ARPEGE/ALADIN NWP system. Mon. Weather Rev. 123, 515-535. https://doi.org/10.1175/1520-0493(1995)123<0515:IOTFEE $>2.0 . C O ; 2$

Cardinali, C., 2009: Monitoring the observation impact on the short-range forecast. Quart. J. Roy. Meteor. Soc. 135, 239-250. https://doi.org/10.1002/qj.366

Daley, R., 1991: Atmospheric Data Analysis. Cambridge Univ. Press.

EUCOS Space-Terrestrial Study Final Report: Observing System Experiments from the winter 2004 2005 and summer 2005. METNO report: 7/2007.

Fischer, A., Homonnai, V., Mile, M., Sepsi, P., Szintai, B., and Szücs, M., 2017: Modelling activities at the Hungarian Meteorological Service. ALADIN-HIRLAM newslett. 8, 64-68.

Fischer, C., Montmerle, T., Berre, L., Auger, L., and Stefănescu, A., 2005: An overview of the variational assimilation in the ALADIN/FRANCE NWP system. Quart. J. Roy. Meteor. Soc.131, $3477-$ 3492. https://doi.org/10.1256/qj.05.115

Geer, A.J., 2016: Significance of changes in medium-range forecast scores. Tellus A 68,1(30229), 1-21. https://doi.org/10.3402/tellusa.v68.30229

Gelaro, R., Zhu, Y., and Errico, R., 2007: Examination of various-order adjoint-based approximations of observation impact. Meteorol. Zeitsch. 16, 685-692. https://doi.org/10.1127/0941-2948/2007/0248

Hall C., 1987: A common verification scheme for limited area models. EWGLAM Newsletter 15, 144-147.

Horányi, A., Ihász, I., and Radnóti, G., 1996: ARPEGE/ALADIN: A numerical weather prediction model for Central-Europe with the participation of the HMS. Idöjárás 100, 277-301.

Kalnay, E., 2002: Atmospheric Modeling, Data Assimilation and Predictability. Atmospheric Modeling. Cambridge University Press. https://doi.org/10.1017/CBO9780511802270 
Lawrence, H., Bormann, N., Sandu, I., Day, J., Farnan, J., and Bauer, P., 2019: Use and impact of arctic observations in the ecmwf numerical weather prediction system. Quart. J. Roy. Meteorol. Soc., 145, 3432-3454. https://doi.org/10.1002/qj.3628

Mile, M., Bölöni, G., Randriamampianina, R., Steib, R., and Kucukkaraca, E., 2015: Overview of mesoscale data assimilation developments at the Hungarian Meteorological Service, Időjárás $119,215-239$.

Radnoti, G., Bauer, P., McNally, A., and Horanyi, A., 2012: ECMWF study to quantify the interaction between terrestrial and space-based observing systems on numerical weather prediction skill. ECMWF Techn. Memor. 679.

Randriamampianina, R., 2005. Radiance-bias correction for a limited area model, Időjárás 109, 143-155.

Randriamampianina, R., 2006a: Investigation of the AMV data derived from meteosat- 8 in theALADIN/HU assimilation system. 8th International Winds Workshop, 24-28 April 2006, Beijing, China. Access available on 09.05.2021, from:

https://www-cdn.eumetsat.int/files/2020-04/pdf_conf_p47_s2_06_randriama_v.pdf

Randriamampianina, R., 2006b: Impact of high resolution satellite observations in the ALADIN/HU model, Idöjárás 110, 329-347.

Randriamampianina, R.; Schyberg, H.; and Mile, M., 2019: Observing System Experiments with an Arctic Mesoscale Numerical Weather Prediction Model. Remote Sens. 11, 981; https://doi.org/10.3390/rs11080981

Randriamampianina, R., N. Bormann, M. A., Ø. Køltzow, H. Lawrence, I. Sandu, and Z.-Q. Wang, 2021: Relative impact of observations on a regional Arctic numerical weather prediction system, Quart. J. Roy. Meteor. Soc.147, 2212-2232. https://doi.org/10.1002/qj.4018

Parrish, D. and J. Derber, 1992: The National Meteorological Center's spectral statistical-interpolation analysis system. Mon. Weather Rev. 120, 1747-1763. https://doi.org/10.1175/1520-0493(1992)120<1747:TNMCSS $>2.0 . C O ; 2$

Soldatenko, S., Tingwell, C., Steinle, P., and Kelly-Gerreyn, B.A., 2018: Assessing the impact of surface and upper-air observations on the forecast skill of the access numerical weather prediction model over Australia. Atmosphere 9, 23. https://doi.org/10.3390/atmos9010023

Saunders, R.W., Matricardi, M., Brunel, P., English, S.J., and Deblonde, G. ,2002: RTTOV-7: A Satellite Radiance Simulator for the New Millennium. Proceedings of the XIIth International TOVS Study Conference, Lorne, Australia, 28 February - 5 March 2002.

Termonia, P. Fischer, C., Bazile, E., Bouyssel, F., Brožková, R., Bénard, P., Bochenek, B., Degrauwe, D., Derková, M., El Khatib, R., Hamdi, R., Mašek, J., Pottier, P., Pristov, N., Seity, Y., Smolíková, P., Španiel, O., Tudor, M., Wang, Y., Wittmann, C., and Joly, A., 2018: The ALADIN System and its canonical model configurations AROME CY41T1 and ALARO CY40T1. Geosci. Model Dev. 11, 257-281. https://doi.org/10.5194/gmd-11-257-2018

Tóth, H., Homonnai, V., Mile, M., Várkonyi, A., Kocsis, Zs., Szanyi, K., Tóth, G., Szintai, B. and Szépszó, G., 2021: Recent developments in the data assimilation of AROME/HU numerical weather prediction model. Idöjárás 125, 521-553. https://doi.org/10.28974/idojaras.2021.4.1

Thyness V.W. and Schyberg H., 2007: EUCOS Space-Terrestrial Study Final Report: Observing System Experiments from the winter 2004 - 2005 and summer 2005. METNO report: 7/2007. 